\title{
O uso da ferramenta cognitiva Fórum no processo de ensino-aprendizagem na modalidade a distância
}

\author{
Danielli Veiga Carneiro Sondermann¹, Yvina Pavan Baldo \\ ${ }^{1}$ Centro de Referência em Formação e em Educação a Distância (Cefor) - Instituto \\ Federal do Espírito Santo - Serra, ES - Brasil \\ ${ }^{2}$ Centro de Referência em Formação e em Educação a Distância (Cefor) - Instituto \\ Federal do Espírito Santo - Serra, ES - Brasil \\ \{danielli, yvina\} @ifes.edu.br
}

\begin{abstract}
This article qualitative, shows a cutout of an action research in the area of Educational Design Inclusive on the settings of cognitive tool Forum and the impacts caused the interaction of student-student, student-tutor and student-teacher. The research was conducted in a training course for Distance Education at a public institution of education. The action research was organized with three focus groups: Group 1 - production team, Group 2 Teachers; Group 3 - Students, among students with visual disabilities and three deaf. The results reinforce the importance of the form of mediation as a factor of success for the construction of knowledge.
\end{abstract}

Resumo. Este artigo de cunho qualitativo, apresenta um recorte de uma pesquisa-ação na área de Design Educacional Inclusivo sobre as configurações da ferramenta cognitiva Fórum e os impactos causados na interação do aluno-aluno, aluno-tutor e aluno-professor. A pesquisa foi realizada em um curso de formação para Educação a Distância em uma instituição pública de ensino. A pesquisa-ação foi organizada com três grupos focais: Grupo 1 - equipe de produção, Grupo 2 - Professores; Grupo 3 Alunos, dentre os alunos um com deficiência visual e três surdos. Os resultados reforçam a importância da forma de mediação como fator de sucesso para a construção do conhecimento.

\section{Introdução}

O crescimento da Educação a Distância $(\mathrm{EaD})$ no Brasil tem impulsionado uso das Tecnologias de Informação e Comunicação (TICs) nas práticas educacionais, independente da modalidade de ensino. Entretanto, ainda tem-se muitos desafios para se utilizar as ferramentas disponíveis de maneira efetiva para que a aprendizagem realmente aconteça.

A Educação a Distância tem proporcionado ações em prol do aumento no número de matrículas em regiões distantes das instituições presenciais de ensino e também ações em torno da Educação Inclusiva, sobretudo, em questões de deficiência física com dificuldade de deslocamento, e, ainda, naquelas deficiências que necessitam de material acessível, por exemplo, a deficiência visual e a surdez.

Uma das ferramentas cognitivas muito utilizadas na EaD é o Fórum, uma ferramenta assíncrona de uso 'simples' para comunicação textual, mas em alguns momentos, o número excessivo de mensagens para quem não realiza o 
acompanhamento diário, pode tornar-se algo 'complexo'. Por meio das possíveis interações entre aluno-aluno, aluno-tutor e aluno-professor é possível a construção do conhecimento, por meio de troca de ideias, sugestões, elogios e impressão, a qualquer momento de um curso, salvo nos casos, em que os tempos são demarcados previamente.

Este artigo tem como objetivo apresentar um recorte de uma pesquisa-ação na área de Design Educacional Inclusivo sobre a construção, o uso e a avaliação de um Fórum em uma disciplina na modalidade a distância em um curso de formação de professores em uma instituição pública.

\section{O uso do Fórum da modalidade a distância}

Os cursos na modalidade a distância, normalmente, são planejados por meio de alguma matriz ou mapa de atividades que detalha todos os conteúdos, os objetivos, as atividades, os recursos utilizados e a forma de avaliação. Os iniciantes desta modalidade tem dificuldade em indicar qual a ferramenta mais indicada para determinado conteúdo, daí a importância do acompanhamento de um designer educacional junto ao professor durante este planejamento e acompanhamento durante toda a oferta de uma componente curricular e/ou um curso.

Os pressupostos apresentados por Nevado, Carvalho e Menezes (2009) potencializam a construção dos mapas de atividades, que muitas vezes, erroneamente, são caracterizados como algo 'engessado' e servem de críticas contra a EaD. Estes autores, propõem por meio de articulação teórico-prática, estratégias interativas e problematizadoras, currículos flexíveis, materiais interativos na Internet e práticas interdisciplinares. E os fóruns são ferramentas cognitivas que auxiliam e muito na interação da $\mathrm{EaD}$.

O Quadro 1 apresenta os principais tipos de configuração de um Fórum extraídos de um Ambiente Virtual de Aprendizagem (AVA), no caso o Moodle:

QUADRO 1 - Tipos de Fórum

\begin{tabular}{|l|l|}
\hline Tipo de Fórum & Descrição \\
\hline $\begin{array}{l}\text { Discussão } \\
\text { simples }\end{array}$ & $\begin{array}{l}\text { É um único tópico em uma única página. Normalmente é usado para } \\
\text { organizar discussões breves com foco em um tema preciso. }\end{array}$ \\
\hline Fórum geral & $\begin{array}{l}\text { É um fórum aberto, onde todos os participantes podem iniciar um novo } \\
\text { tópico de discussão quando quiserem. }\end{array}$ \\
\hline $\begin{array}{l}\text { Cada usuário } \\
\text { inicia } \\
\begin{array}{l}\text { UM } \\
\text { tópico }\end{array}\end{array}$ & $\begin{array}{l}\text { Cada participante pode abrir apenas um novo tópico de discussão, mas } \\
\text { todos podem responder livremente as mensagens, sem limites de } \\
\text { quantidades. Este formato é usado, por exemplo, nas atividades em que cada } \\
\text { participante apresenta um tema a ser discutido e atua como moderador da } \\
\text { discussão deste tema. }\end{array}$ \\
\hline $\begin{array}{l}\text { Fórum } \\
\text { Perguntas } \\
\text { Respostas }\end{array}$ & $\begin{array}{l}\text { Neste fórum um estudante pode ler as mensagens de outros somente após a } \\
\text { publicação de sua mensagem. Depois disto pode também responder às } \\
\text { mensagens do grupo, isto permite que a primeira mensagem de cada } \\
\text { estudante seja original e independente. }\end{array}$ \\
\hline
\end{tabular}

Fonte: Moodle (2012).

A configuração de um Fórum pode ajudar na interação, mas sabe-se que quem faz a interação é uma 'pessoa' com outra 'pessoa', ou seja, a tecnologia é um meio. 
Moore (2002) desenvolveu o conceito de 'distância transacional', que vai para além da distância geográfica ou temporal, sendo, sobretudo, um conceito pedagógico. É um conceito que descreve o universo de relações professor-aluno quando estes estão separados no espaço-tempo. Existe grupos de variáveis voltadas para o ensino e a aprendizagem, que influenciam na distância transacional: o diálogo, a estrutura e a autonomia do aluno (MOORE, 1989). Para Moore (2002) quanto mais os materiais didáticos forem estruturados maior é a distância transacional e vice-versa. Dado que os fóruns são alimentados pela interação humana, pressuponha-se que menor será a distância transacional.

O Quadro 2 apresenta os diferentes tipos de agregação de notas nos fóruns do Moodle. A escolha pelo tipo de agregação também pode influenciar no número de interações em um fórum, pois alguns discentes 'ainda' se preocupam com a 'nota' e não com sua aprendizagem e compartilhamento de ideias.

QUADRO 2 - Tipos de Agregação de Notas nos Fóruns do Moodle

\begin{tabular}{|l|l|}
\hline $\begin{array}{l}\text { Tipo de } \\
\text { Agregação }\end{array}$ & Descrição \\
\hline Média (padrão) & $\begin{array}{l}\text { A média de todas as notas dadas para as postagens no fórum. Isto é } \\
\text { especialmente útil quando existe uma grande quantidade de notas sendo } \\
\text { dadas. }\end{array}$ \\
\hline Conta & $\begin{array}{l}\text { O número de postagens que receberam notas é a nota final. Isto é útil } \\
\text { quando o número de postagens é importante. Observe que o total não } \\
\text { pode exceder a nota máxima permitida para o fórum. }\end{array}$ \\
\hline Máximo & $\begin{array}{l}\text { A nota mais alta é a nota final. Este método é útil para enfatizar o melhor } \\
\text { trabalho do participante, permitindo que eles façam uma postagem com } \\
\text { ótima qualidade e outras postagens mais casuais. }\end{array}$ \\
\hline Mínimo & $\begin{array}{l}\text { A menor nota é escolhida como a nota final. Este método promove a } \\
\text { cultura de alta qualidade para todas as postagens. }\end{array}$ \\
\hline Soma & $\begin{array}{l}\text { Todas as notas para cada usuário são somadas. Observe que o total não } \\
\text { pode exceder a nota máxima para o fórum. }\end{array}$ \\
\hline
\end{tabular}

Fonte: Moodle (2012).

\section{Metodologia}

Este artigo traz a discussão dos resultados de uma pesquisa-ação e foi organizada em três grupos focais: Grupo 1 - equipe de produção, no intuito de avaliar os problemas referentes ao processo de criação de materiais para EaD no âmbito do UDL; Grupo 2 Professores do Curso de Capacitação em EaD, responsáveis pelo planejamento visando ao uso do UDL; Grupo 3 - Alunos do curso de Capacitação em EaD. A pesquisa foi realizada em uma instituição pública de ensino no período de Agosto/2012 a Junho/2014.

Hugon e Seibel (1986, p. 13) definem a pesquisa-ação da seguinte forma: "Tratase de pesquisas nas quais há uma ação deliberada de transformação da realidade; pesquisas que possuem um duplo objetivo: transformar a realidade e produzir conhecimentos relativos a essas transformações".

Todas as reuniões foram gravadas, transcritas e depois discutidas com o grupo para a tomada de decisões sobre os ciclos da pesquisa-ação, composto pelas seguintes fases: definição de um problema, pesquisa preliminar, hipótese, desenvolvimento de um Plano de Ação, implementação do Plano de Ação, coleta de dados para avaliação dos 
efeitos da implementação do plano, avaliação do Plano de Intervenção e comunicação dos resultados.

Devido à falta de alunos com deficiência nos cursos a distância da instituição pesquisada, optou-se em usar a própria Formação de Professores para Educação a Distância (EaD) convidando os alunos com deficiência, graduandos e/ou graduados, para realizar a mesma e fazerem parte da pesquisa. Depois de uma ampla divulgação por meio de redes sociais, listas de discussão e contato com alguns profissionais, alcançouse dois alunos deficiente visuais e três alunos surdos.

A Formação de Professores para Educação a Distância tem sido ofertada desde 2009 pela instituição pesquisada, inicialmente com uma carga horária de $180 \mathrm{~h}$ e que a partir de 2011 foi alterada para 200h, devido à solicitação feita pelos professores e alunos participantes de cursos anteriores. A matriz curricular atual é formado pelas seguintes disciplinas: Ambiente Virtual de Aprendizagem (60h), Fundamentos da Educação a Distância (30h), Planejamento de Materiais para Educação a Distância (60h), Tecnologias da Informação e Comunicação (20h) e Mídias para Educação a Distância (30h).

\section{Coleta e análise dos resultados}

Neste artigo, optou-se por apresentar os recortes referente a uma análise feita em um dos fóruns do curso na disciplina de Planejamento de Materiais para Educação a Distância, cujo enunciado é apresentado na Figura 1.

\section{Olá!}

Chegou a hora de você planejar a sua disciplina (ou curso, como já mencionamos na Agenda da Semana). Esta atividade será realizada em 2 (duas) etapas:

1) crie um mapa de atividades - versão 1 de acordo com o arquivo modelo e poste um tópico com o nome de sua disciplina e o seu primeiro nome. Em seguida, anexe o arquivo no tópico criado e escreva sobre os principais desafios e/ou dificuldade que teve para realizá-lo no Fórum. Lembre-se de diversificar os procedimentos de ensino e estratégias de aprendizagem.

2) comente e/ou dê sugestões sobre o mapa de atividades apresentado por seu colega de curso.

\section{Atenção!}

Antes de construir o mapa de atividades, verifique com o designer instrucional e/ou o coordenador de curso as seguintes questões: o número de semanas que possui sua disciplina, a existência do calendário de provas e a semana de parada obrigatória. Conhecer o projeto político pedagógico do curso também é importante para evitar sobreposição de conteúdos e também para criar um material que atenda aos objetivos do curso. Caso você esteja criando um curso não existente ainda, pense em seu público-alvo e nas questões a eles referentes, e só após elabore seu mapa.

Valor:30 pontos.

\section{Figura 1 - Enunciado da atividade para construção do Mapa de Atividades Fonte: A Autora.}

De acordo com a Figura 1, o fórum é utilizado para divulgar o mapa de atividades criado pelo aluno, incluindo um comentário sobre os desafios e/ou dificuldades encontradas para realizá-lo, e, também, solicita-se comentários as postagens dos outros colegas. Um dos alunos reforçou a dificuldade enfrentada pelos iniciantes da EaD sobre qual recurso utilizar:

Trata-se do primeiro mapa (primeira vez é sempre mais difícil), dúvidas quanto à tempo de cada aula, dúvida de que recurso utilizar, 
CBIE-LACLO 2015

Anais do XXI Workshop de Informática na Escola (WIE 2015)

saber dosar conteúdo (medo de não ficar muito extenso para disciplina EAD), insegurança se conseguirei em tempo hábil montar os vídeos e trabalhos sugeridos no mapa e dúvidas de algumas nomenclaturas (editor de texto, por exemplo. A gente usa word, mas não sei se é certo citar ou generalizar) - Aluno da Capacitação, via Fórum, 18/05/2013.

Como no enunciado da atividade (Figura 1) propunha-se a realização de comentários sobre os mapas de atividades de outros colegas, percebemos que as pessoas da mesma área de conhecimento discutiam mais sobre conteúdo em si e de áreas diferentes apenas sobre os recursos e diversificação dos mesmos. Muitos alunos por iniciativa própria, ao lerem as sugestões de melhorias já enviavam nova versão, atividade esta que estava prevista para acontecer na próxima semana da disciplina.

Os enunciados propostos nos fóruns em cursos na modalidade a distância devem potencializar a discussão e a autoavaliação sobre a atividade realizada:

As demais atividades que não continham nada no enunciado sobre comentários sobre o processo de realização das atividades propostas, foram realizadas de maneira operacional, distanciando o professortutor sobre as dificuldades encontradas e formas de superá-las. Aqui cabe uma primeira reflexão: É preciso deixar claro nos enunciados sobre a atividade proposta e a realização de uma autoavaliação sobre o desenvolvimento da mesma. Dessa forma é possível levar o aluno a refletir sobre o processo desenvolvido na solução das atividades propostas fazendo com que o mesmo tome consciência sobre a sua aprendizagem (SONDERMANN; PINEL; NOBRE; 2012).

Ao analisarmos esta atividade relacionada à construção do mapa de atividades percebeu-se que por mais que o enunciado solicitasse comentários sobre outro colega do curso, questões ricas surgiram ao longo da disciplina e nem todos participavam, ao menos no que diz respeito a tecer comentários, pois conforme já apresentado por Mattar (2009), tem-se um tipo de interação chamada de 'vicária', onde o aluno lê, mas não comenta.

Optou-se durante a análise do fórum uma correlação entre os tipos de fóruns e os impactos da forma de interação humana. No tipo Discussão Simples (Figura 2), esse tipo de configuração está diretamente relacionado ao enunciado proposto. Se cada aluno tiver que colocar sua opinião sobre uma questão macro, ele pode entrar no fórum e responder, independente da resposta de outros participantes. Por outro lado, dependendo do número de alunos, a exigência das leituras de todas as postagens, pode ser muito bem sucedida na questão da construção coletiva do conhecimento, mas pode gerar desmotivação aos alunos que 'tendem' ao trabalho mais individualizante. 
CBIE-LACLO 2015

Anais do XXI Workshop de Informática na Escola (WIE 2015)

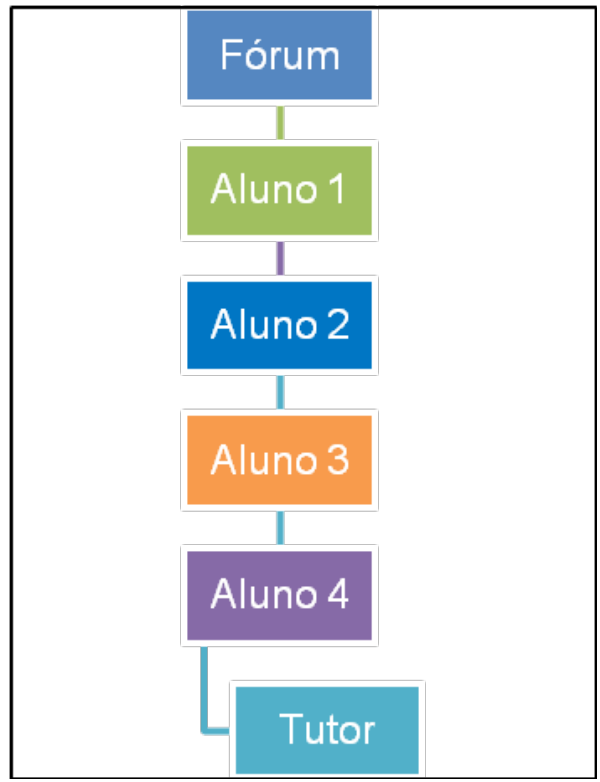

Figura 2 - Fórum Discussão Simples Fonte: A Autora

O Fórum Geral (Figura 3) foi amplamente utilizado no curso pesquisado, normalmente os enunciados solicitavam a criação de um novo tópico e cada participante deveria escolher um colega para comentar. Esse tipo de atividade deve ser utilizado quando tem-se projetos individuais e que deseja-se receber feedbacks de outros participantes. Este tipo de configuração não é muito indicado para a promoção de debate único. O comportamento dos tutores é bem semelhando ao fórum de Discussão Simples, pois este não consegue agregar todas as questões dado que os tópicos são criados em separado.

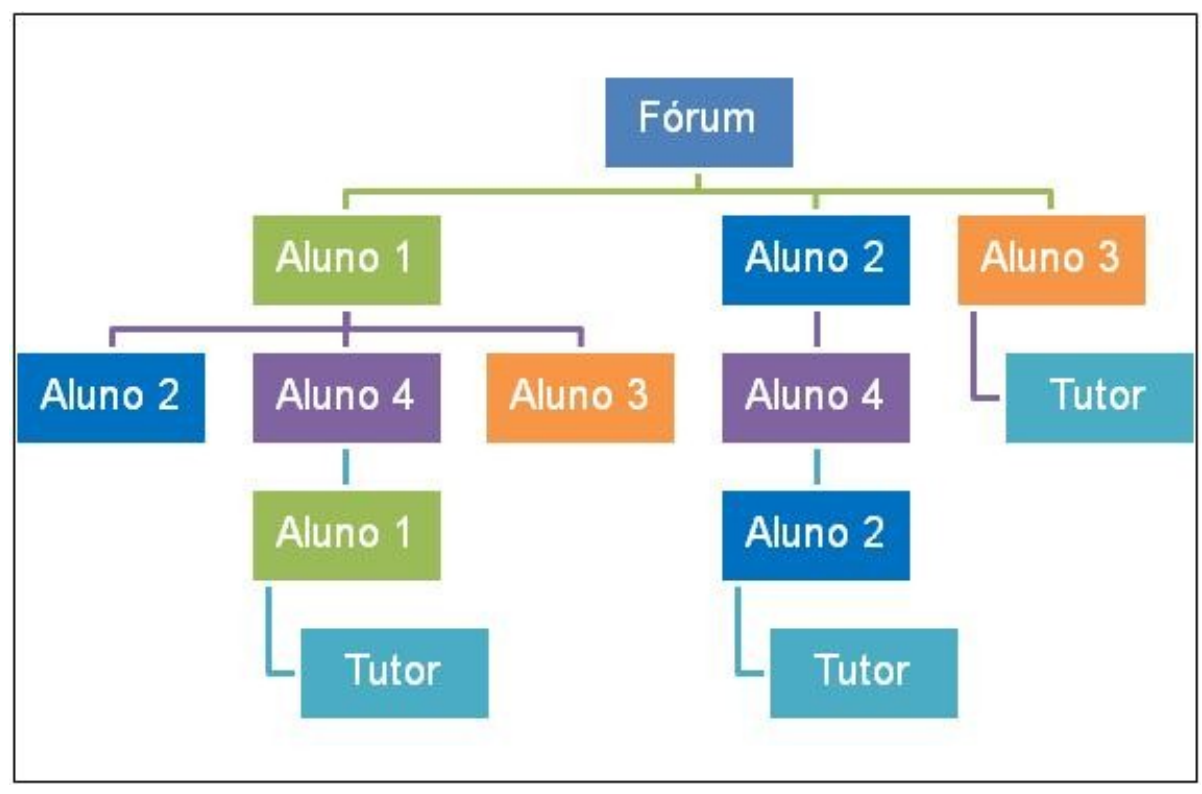

Figura 3 - Fórum Geral

Fonte: A Autora 
Outra configuração que o Fórum permite é a criação de apenas 'um' novo tópico, na pesquisa não foi encontrado esse tipo de configuração, e sim o uso do Fórum Geral funcionando dessa forma, pois o próprio enunciado sugeria a criação de um tópico. A 'habitação' pelos participantes do fórum se dará de acordo com enunciado conforme já apresentado, pois alguns alunos, por iniciativa própria não colaboram com os colegas e/ou receiam pela pseuda 'invasão' ao espaço do outro. Na Figura 4, apresenta-se um modelo que apesar do uso do fórum a interação se dá somente entre o tutor e o aluno.

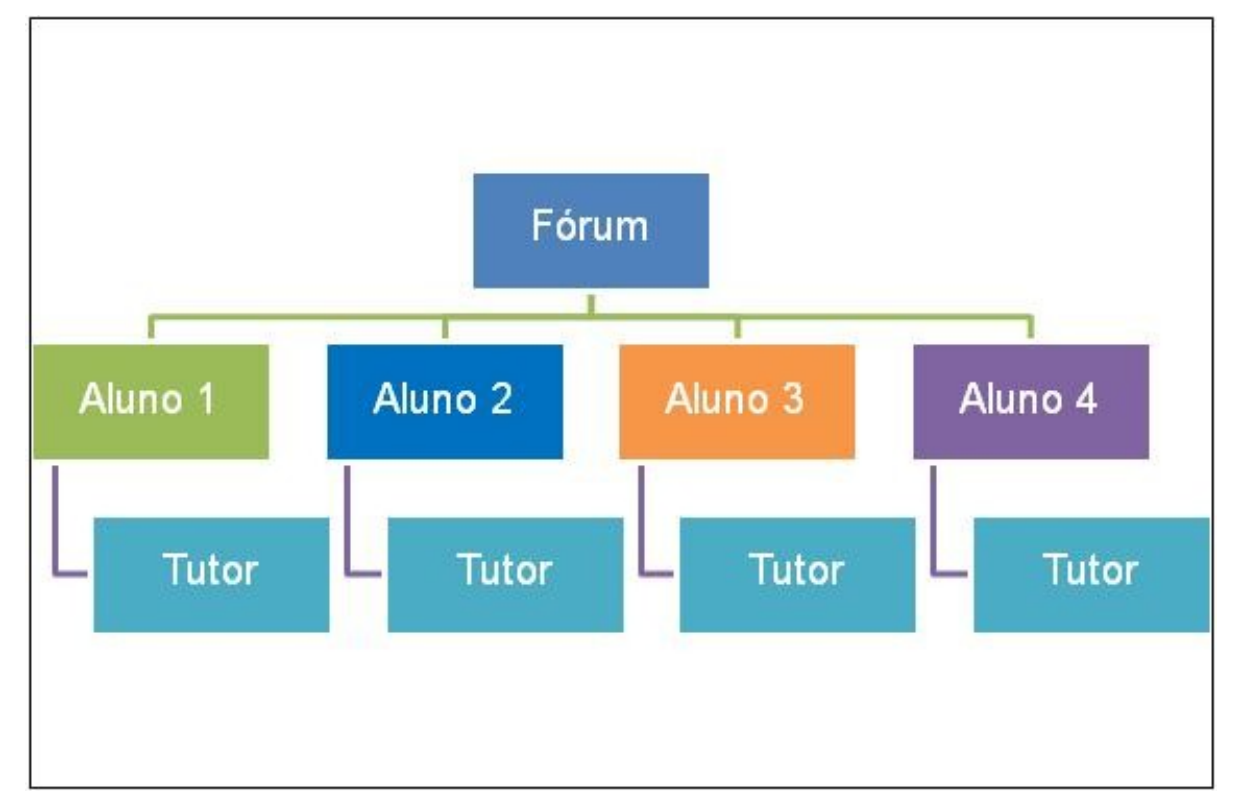

Figura 4 - Fórum: cada usuário inicia apenas UM NOVO TÓPICO Fonte: A Autora

Não foi encontrado fóruns configurados como Perguntas e Respostas, achamos muito importante a ideia da originalidade e da independência, ou seja, sobre a possibilidade de só deixar o aluno ler as mensagens após sua postagem. Ao levar a discussão ao grupo focal, percebeu-se todos desconheciam este tipo de configuração.

A Figura 5 apresenta um esquema conceitual do que tem-se como resultado da análise na ótica de um processo de construção coletiva do conhecimento, o ideal é que os alunos não sejam 'forçados' a participar por meio de uma premiação por nota, mas que o aluno compreenda que ele pode contribuir e aprender com o outro, seja ele um colega um tutor e/ou um professor. 
CBIE-LACLO 2015

Anais do XXI Workshop de Informática na Escola (WIE 2015)

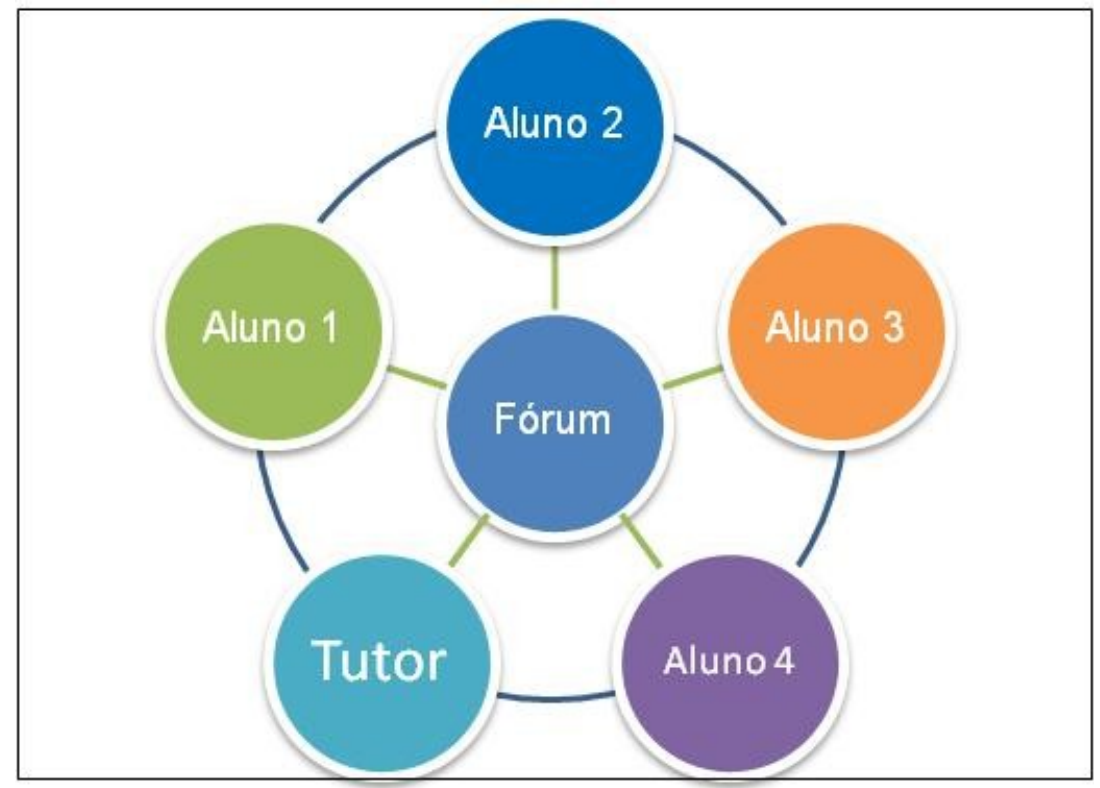

Figura 5 - Fórum DESEJÁVEL

Fonte: A Autora

Os fóruns do curso puderam ser acompanhados com sucesso pela deficiente visual dado aos benefícios do uso dos leitores de tela dos computadores. $\mathrm{O}$ excerto a seguir reforça a motivação da aluna deficiente visual:

Agora estou consciente do que é ser um aluno EaD. Acredito que eu já disse que aprendi aqui neste curso que os fóruns e outros espaços é para promover principalmente a interação entre os alunos. Puxa! Muda muito o tua percepção quanto o AVA ao entender isto. Eu de preconceituosa da EaD a uma apaixonada, mas não cega! É uma paixão que liberta! Um dia ainda vou dar um abração em vocês dois (tá bom no prof. [nome ocultado]; na [nome ocultado] e no [nome ocultado]), não darei abraço no prof. [nome ocultado] o material dele sobre Web, puxa deu um trabalhão para acessar (brincadeira, que seria da vida sem está dificuldade toda) brincadeira - Aluna deficiente visual, via e-mail, 06/09/2013, por e-mail.

Entretanto, os alunos com surdez, ainda é um desafio sem a presença dos intérpretes durante todo o curso, pois sem a leitura e a escrita adequada da língua portuguesa, mesmo em alunos que já possuem graduação, houve muita dificuldade por parte dos alunos, apesar de todos os esforços para não desistirem do curso. Não basta apenas colocar todo o material e as atividades do curso em Libras é preciso um tutor fazendo a mediação, por meio de vídeos em Libras para os alunos surdos e em português para que os ouvintes também possam interagir com os colegas surdos.

Nas reuniões do grupo focal sempre foi ressaltada a ideia de que um curso de formação deva inspirar os alunos, portanto, desde a concepção do tipo de configuração do fórum, a forma de avaliação e, o mais importante, a forma de interação é que irá fazer a diferença no processo de formação. A tendência é que os alunos reproduzam as experiências bem sucedidas com adaptações ao currículo dos cursos a qual estão vinculados. 


\section{Considerações finais}

O crescimento das tecnologias na educação nem sempre tem sido acompanhado por todos os docentes, em se tratando de fóruns é importante o conhecimento de cunho técnico para estimular a interação, entretanto, muito mais do que este tipo de conhecimento e/ou acompanhar o novo recurso disponível e/ou nova configuração, o papel docente enquanto mediador é que fará a diferença no processo de construção de conhecimento dos envolvidos nos cursos na modalidade a distância.

A sabedoria em calar-se nos momentos de interação de algo ainda em construção e que necessita de maturação, a intervenção no momento adequado, o elogio aos alunos, a crítica na dosagem correta, a afetividade nos momentos necessários, o estímulo aos ausentes, a humildade em dar espaço aos alunos que podem contribuir mais para o debate do que o próprio o docente dentre outras inúmeras questões de quando relacionados ao fato de vivermos em sociedade para além dos espaços escolares.

Este trabalho apresentou questões importantes sobre a construção de um fórum, as diferentes formas de uso e os impactos sobre a formas de interação. Também foi apresentado sobre as diferentes configurações de avaliação de um fórum.

E também reforçou as possibilidades por meio da modalidade distância para os deficientes visuais e os desafios ainda a serem superados pelos surdos. A EaD, assim como o ingresso dos alunos com deficiência é um fato, que tende a crescer a cada ano e que as instituições de ensino devem estar preparadas.

\section{Referencias}

MATTAR, J. Interatividade e aprendizagem. In: LITTO, F. M.; FORMIGA, M. (Orgs). Educação a distância: o estado da arte. São Paulo: Pearson Education do Brasil, 2009.

MOORE, Michael G. Teoria da Distância Transacional. Revista Brasileira de Aprendizagem Aberta e a Distância, São Paulo, Ago, 2002. Disponível em: < http://www.abed.org.br/revistacientifica/Revista_PDF_Doc/2002_Teoria_Distancia_ Transacional_Michael_Moore.pdf>. Acesso: 23 maio. 2012.

NEVADO, Rosane A.; CARVALHO, Marie J. S; MENEZES, Crediné S. Inovações na formação de Professores na modalidade a distância. Revista Educação Temática Digital. v. 10, $\mathrm{n}^{\circ}$ 2, p. 373-393, Campinas, 2009. Disponível em: < http://www.fae.unicamp.br/revista/index.php/etd/article/view/2031>. Acesso: 15 jul. 2013.

SONDERMANN, Danielli V. C.; PINEL, Hiran; NOBRE, Isaura A. M. Rede Afetiva do Design Universal para Aprendizagem na educação 2.0: reflexões e possibilidades. In: $18^{\circ}$ Workshop de Informática na Escola (WIE) 2012. Universidade Federal do Rio de Janeiro. Anais... Disponível em: <http://www.brie.org/pub/index.php/wie/article/view/2117>. Acesso em: 24 jul. 2013. 